\title{
Keeping Up with the Psychiatric Literature: A Survival Guide
}

\author{
Joel Yager ${ }^{a}$ Steven L. Dubovsky ${ }^{b}$ Peter P. Roy-Byrne ${ }^{c}$ \\ ${ }^{a}$ Department of Psychiatry, University of Colorado School of Medicine, Aurora, CO, USA; ${ }^{b}$ Department of Psychiatry, \\ State University of New York at Buffalo, Buffalo, NY, USA; ${ }^{\mathrm{C} D e p a r t m e n t}$ of Psychiatry and Behavioral Sciences, \\ University of Washington School of Medicine, Seattle, WA, USA
}

Most psychiatrists aspire to follow professional imperatives for lifelong learning, which requires remaining current with the medical literature. However, while information overload in psychiatry has been appreciated for decades [1], this overload is accelerating and becoming increasingly difficult to manage. In 2019, the last year for which data are available, more than 3,000 articles were published each month in 545 professional journals specializing in psychiatry and psychology [2]. However, our experience over the past 25 years as editors of the New England Journal of Medicine's Journal Watch Psychiatry, a professional newsletter reviewing new findings, suggests that only the smallest fraction of these articles contains information with the potential to be "practice changing" or even clear relevance to current practice. Moreover, many clinical trials, practice guidelines, and reviews suffer from influences of industry and other interests. In addition to assessing such influences, it is necessary to determine whether new research findings can be taken at face value or require further validation. Thus, "keeping up" now means finding and critically evaluating the relatively small number of truly informative findings in mountains of information [3]. Based on these considerations, the aim of this editorial is to offer practitioners and

karger@karger.com

(c) 2021 S. Karger AG, Basel

www.karger.com/pps

Karger! trainees brief useful initial strategies for productively and efficiently keeping up with the psychiatric literature according to the preferences, interests, and available time of the clinician.

In addition to a general desire for knowledge, motivations to keep up with the medical literature vary. Some clinicians are broadly interested in the entire field, while other have more focused interests. Some are "early adapters," desiring to try new treatments as soon as possible. Others want to remain aware of new data relevant to their current practices. Many practitioners are obliged to respond to increasingly complicated questions from patients and families who request treatments they see reported on conventional media, social media, and various websites [4]. In some countries, following the medical literature is now required to maintain certification or licensures, and lifelong learning is correlated with career satisfaction internationally [5].

For many years, clinicians' primary sources of information about new medications and devices involved presentations, often accompanied by meals and sponsored by manufacturers, but industry-sponsored presentations have recently become less popular [6]. Concurrently, electronic forms of information about new treatments 
have become widely available. Residents and practitioners employed by healthcare institutions can usually access digital libraries offering full-text access to many journals, the Cochrane database, electronic books, and subscription textbooks such as the internationally available UpToDate. Independent practitioners can access numerous internet resources, including Wikipedia, PubMed, and Medscape. However, Wikipedia is not peer reviewed, the quality of information is not guaranteed, and much of this information is only available in English. Unless they explicitly unsubscribe, many clinicians are deluged with trade newspapers, free journals, and email push services filled with teasing headlines and new products. A growing number of print and electronic journals, newsletters, online continuing education courses, and podcasts are easily accessible. Printed material is more popular in developing countries, while electronic sources are preferred in developed countries [5]. European residents prefer to learn from online journals, books, institutional free-access scientific websites, and senior colleagues, with industry being the least preferred source of information [5]. However, European residents continue to access industry-provided educational materials [7]. Readers fluent in languages other than English can read the many excellent journals published in those languages in their entirety. For example, the Canadian Journal of Psychiatry publishes articles in French and English. Highly respected journals published in other languages include Encephale (French), Harefuah (Hebrew), Nervenarzt (German), Actas Españolas de Psiquiatría (Spanish and English), Rivista di Psichiatria (Italian and English), Revista Brasileira de Psiquiatria (Spanish, Portuguese, and English), and the Japanese Journal of Psychiatry and Neurology (Japanese). English language abstracts for many articles published in these journals may be available on the PubMed website. World Psychiatry, a very high-impact journal, is published in Arabic, Chinese, English, French, Russian, Spanish, and Turkish.

How these diverse materials are used depends on specific interests of the information seeker, the depth of knowledge desired, and the time and effort devoted to keeping up. Some clinicians may wish to encompass the universe of biopsychosocial data, or they may be more focused. Similarly, some hope to master a particular topic in depth, for example detailed pharmacokinetics, pharmacodynamics, molecular mechanisms of action, and every drug interaction, before they will prescribe a new treatment, whereas others are satisfied to know the starting doses and major adverse effects. Individuals also differ in their ability to attend and focus for sustained peri- ods of time, how much they remember under various learning circumstances, and time constraints. Some people reserve specific times for literature research, whereas others prefer reading during odd free moments or just before a patient encounter. Some find their attention and focus to be highest when provoked by challenging concerns connected to recent clinical encounters, whereas others follow the same topic for long periods of time.

Information seekers should design their individualized plans for keeping up by also considering their preferred learning styles. For example, does the clinician prefer reading, watching video lectures, or listening to lectures and podcasts? If the preferred option is reading, what are the preferred font sizes, writing styles, density of material, and graphics? Clinicians interested in interpreting statistical conclusions are more likely to review original research, which requires reading printed material in paper or electronic format. Reading from electronic screens imposes different neural burdens than reading from paper pages [8]. To estimate the cognitive load associated with reading professional material, workload calculators can help individuals to roughly approximate the amount of time necessary to read articles of varying length, novelty, and technical difficulty (see, e.g., the now widely disseminated course workload estimator developed at Rice and Wake Forest Universities: Course Workload Estimator; ucdenver.edu). Some clinicians favor solo learning, whereas others learn best via social interactions, as in journal clubs, book clubs, and interactive conferences. Finally, it is important to decide how the new information will be used. For example, European residents were found in one study to continue to believe that newer treatments were more effective than older ones, despite being presented data to the contrary [9].

In what follows, we offer tips concerning varied sources such as peer-reviewed journals, newsletters, psychiatric trade magazines, free journals, web services, blogs, podcasts, and other social media resources [10-12]. Some material already familiar to many readers of this journal is included to assist less experienced consumers of the medical literature. Our aim is to overview available resources that can guide readers to more detailed information about specific sources of information.

Initial Reports of New Research. Major findings are often announced at professional meetings and via university public relations news releases before publication in peer reviewed journals, but initial announcements are not as carefully peer reviewed as are published articles. Findings immediately picked up by news services and broadcast widely via all types of media are the least reliable 
sources of information because they are created by nonscientists whose job is to produce compelling, often grossly oversimplified, headlines designed to attract readers of varying sophistication and attention spans.

Textbooks. Print textbooks are useful sources of wellestablished concepts, but they generally report information at least several years old by the time of publication. Electronic textbooks are updated more frequently (in the case of UpToDate several times per year). Inevitably, some sections may be more recent than others.

Trade Magazines and Newspapers. Several easily accessed professional newspapers and trade magazines available to most trainees and practitioners regularly notify readers of new developments. Publications vary by country and specialty interest. Examples include Psychiatric News and Psychiatric Times in the USA and Inter$A C T$ published by the European Psychiatric Association. Featured articles are mostly written by science writers, but some are solicited from psychiatrists and psychologists considered content experts in the field. While these articles may attempt to disseminate information in balanced and cautious manners, newsletters also include "sponsored content" articles, which are produced under the direction of product sponsors and advertisers and are vulnerable to commercial biases (notably concerning subtle areas of neglect or omission, even if what is included is accurate) [13]. Readers should be wary of any article that advertises a particular treatment as a "breakthrough" or "truly novel" approach. Such language rarely appears in more thoughtful presentations of even the most innovative research. While busy clinicians may appreciate the brevity of these articles and their attention-grabbing graphics, balanced discussions of strengths and weaknesses of the new information is usually absent in brief formats. Such material is only useful if it cites scholarly references that can be consulted for less biased views of the topic. Some free journals whose costs are supported entirely by advertisements contain well-written, concise summaries on current topics. The potential quality of these articles can be judged by the seniority and reputation of their authors and the editorial board and by the comprehensiveness of their references. Of concern, the medical publishing landscape is littered with ersatz journals that lack appropriate peer review [14]. Many of these journals adopt names resembling those of high impact journals to attract readers as well as submissions from inexperienced researchers. Lists of such "predatory" journals are available $[15,16]$. Findings published in these journals require extra high levels of skepticism and scrutiny.

Keeping Up
Web-Based and Social Media Services. Active debate continues regarding the utility of social media for keeping up [17-19]. Most psychiatric journals, trade magazines, and newsletters, and some major universities, academic notables, and enterprising individuals, disseminate headlines, news about their research, and opinions on Facebook, Twitter, Instagram, blogs, and podcasts in order to market their activities. These announcements may alert clinicians to new data but cannot be considered definitive. Even less reliable is the vast amount of material provided by commercial medical education companies of differing quality pushed to email inboxes and social media accounts. The highly condensed information such companies produce to satisfies their sponsors risks bias and superficial reporting. However, such information may alert readers to areas or findings of interest that may warrant examination of the primary journal articles on which these alerts are based.

The Continuing Medical Education (CME) Industrial Complex. Commercial free CME programs offered online or in person are available through national and local professional associations and some universities. These programs increasingly utilize protocols to eliminate influence when they receive industry support. But to be truly free of industry influence, they must charge fees that support all their costs. Proprietary CME companies offer lower fees or "free" programs, but they are usually heavily supported by industry or in some cases are offshoots of manufacturers, resulting in content (and associated exam questions) subject to commercial bias.

Journals. Peer reviewed publications are considered the gold standard of new medical information [20,21]. Among these journals, exceptionally important findings in psychiatry often appear in nonspecialty journals such as the Lancet, the Journal of the American Medical Association, the New England Journal of Medicine, the British Medical Journal, Nature, and Science. Although informative articles may appear in any of the hundreds of psychiatry and psychology journals, the most noteworthy are usually published in a relatively small number of highimpact factor journals. These journals attract top scientists to serve as peer reviewers, providing more stringent review, higher rates of rejection of less-than-excellent submissions, and scientific critiques that enhance the quality of published papers. More specialized articles are more likely to be published in sub-specialty journals. Based on considerable discussion and review, the editors of the New England Journal of Medicine's Journal Watch Psychiatry chose about 60 of these journals from which to abstract and comment on 20-30 important articles each 
month; most articles selected for review appeared in about 20 journals. Based on several measures of journals' influence and prestige and included weighted citations, lists of the top journals in psychiatry have been compiled by SCIImago, a university-based research group focusing on information analysis employing the SCOPUS data base [22], and in Journal Impact Factor (impactfactorforjournal.com) [23] (Table 1).

The first step in utilizing journals is to peruse their online web pages regularly for new content. Most journals invite nonsubscribers to register for electronic notification of newly accepted articles and forthcoming tables of contents, complete with abstracts of the articles. If a particular article is of interest, the next step is to find the full text. Free access to many publications originally in English or translated into English is available at PubMed (https://pubmed-ncbi-nlm-nih-gov.gate.lib.buffalo. edu/?otool $=$ nyublib) and Europe PubMed Central (europepmc.org), along with hints for widening the search to other potential articles of interest (by scrutinizing "similar" or "cited by" articles). In Germany, Livivo offers access to the ZB MED search portal MEDPILOT [24, 25]. Wikipedia collaborates with Translators Without Borders, producing collections of health-related articles in nearly 100 languages and at least some medical content in more than 250 languages [26, 27].

How to Read Journal Articles for Purposes of Keeping Up. A sizeable body of literature exists on how to read the medical literature and use it in practice $[28,29]$. For purposes of screening, the following rules of thumb for approaching articles can save time and effort:

1 If the title is of interest, turn to the conclusions section of the abstract (which might also be labeled with words such as "relevance" or "implications"). If the conclusions are clearly written, readers can judge whether the content is worth pursuing and can then decide whether to read the rest of the abstract [30]. Consider at this point whether the authors overstate the significance of their findings, whether the findings are clinically relevant, and whether the article can be interpreted in simple terms to patients to enhance their understanding of their illnesses.

2 If an article is still intriguing, tables, graphs and illustrations in results sections and discussions often convey the authors' major points concisely. The discussion should put findings in context and point out important limitations in design and findings. Introductory sections are useful if readers would like an overview of the area and a rationale for why the study was undertaken. Going over details of methods and results sections is most useful for researchers and for preparing journal club presentations,
Table 1. Top 20 journals in psychiatry

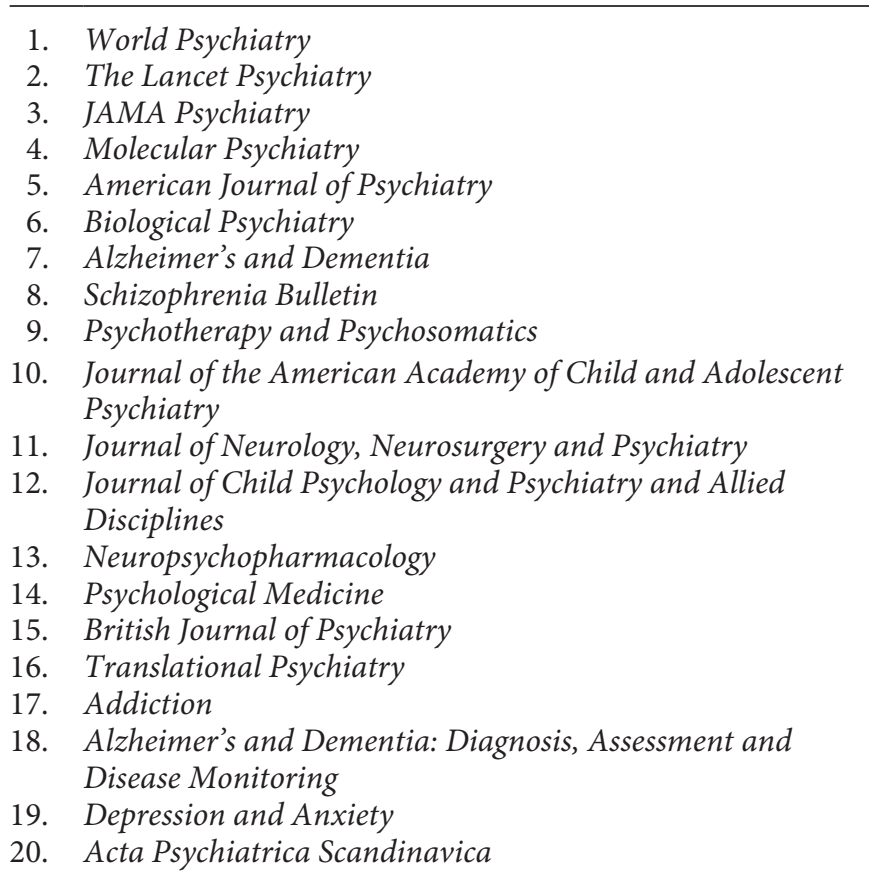

Based on data from Scimago Journal \& Country Rank [22] and Journal Impact Factor [23].

but it is also necessary to decide whether results are valid. Reviews and meta-analyses can be limited by their specific methods, which are often difficult for many clinicians to understand. They may also fail to include unpublished negative trials. Furthermore, although conclusions may apply to "average" patients, they might not apply to a clinician's specific patients [1].

3 It is important to scrutinize funding sources. Even if the research is conducted appropriately, industrysponsored research is designed to demonstrate the superiority of the sponsor's product. Accordingly, industry generally engages experts who are partial to their products to write reviews $[13,31]$. Readers will want to know how closely research populations resemble patients encountered in practice, drop-out rates, the quality of the controls or comparison treatments, and authors' academic and commercial affiliations. To pursue points raised in this editorial in greater detail, further information about complexities of evaluating the literature, such as assessing conflicts of interests, can be found in the references [e.g., $29,32]$.

Practice Guidelines. The American Psychiatric Association, the American Academy of Child and Adolescent Psychiatry, the British National Institute of Clinical Ex- 
cellence (NICE), the Canadian Network for Mood and Anxiety Treatments (CANMAT), and other national, regional, and international associations (in Australia, Spain, and Germany and the World Society of Biological Psychiatry, among others) publish practice guidelines for various disorders. Many guidelines generate treatment algorithms whose executive summaries of recommendations may guide local standards of practice. However, practice guidelines, which tend to emphasize potential benefits over risks, are often based on consensus produced by experts, some of whom may not be active practitioners. Some contributors may have conflicting interests regarding treatments they recommend. Finally, some guidelines may rely too heavily on industry-sponsored studies that do not adequately compare their products with competing treatments [33].

Strategies for Answering "Point of Care" Clinical Questions. Clinicians with pressing needs for "on the spot" information may often rely on Google Search, Google Scholar, or Wikipedia; however, information in these sources is not necessarily reliable. Electronic pharmacology textbooks can be useful to answer specific questions about medication, although information may not always be current. UpToDate, an advertising-free electronic textbook available online via most academic health center libraries and by private subscription, principally focuses on current, succinct, evidence-based information relevant to clinical practice and includes patient education handouts that clinicians can distribute at the point of care. Medscape's Drugs and Diseases sections and editorial content are developed independently of advertising and promotional content. These are most useful for brief overviews of signs and symptoms and for medication dosage ranges, adverse effects, and interactions.

Social Methods for Keeping Up. Whether the need for information is immediate or ongoing, many clinicians learn best from trusted consultants, mentors, and peers. Even following formal training, continuing life-long engagement in regularly scheduled get-togethers designed to disseminate and dissect new literature, using journal club approaches learned during residency, can be useful. These highly social study groups (which can also serve to discuss complex cases) combine opportunities to learn with the benefits of peer support. As is true of our clinical activities, discussing our impressions of published information always helps us to refine and clarify our understanding. Since the pandemic, many groups have switched to remote formats such as Zoom, which some may prefer to continue indefinitely. We know of groups that have met regularly for decades, some broadly based and others focused on specific modalities or disorders (e.g., psychopharmacology and mood disorders). Such groups are most effective when limited in size to about 8-10 individuals.

\section{Conclusions}

The range of resources, strategies, and tactics described in this article may assist readers to identify and efficiently extract relevant information from the masses of new material which deluge us. Integrating new findings into the care of complex patients who may not resemble those in research studies can be additionally helped by ongoing discussions with our peers and consultants. These trusted colleagues can help us to better evaluate new findings and deal with complex clinical challenges, and they may have just read something new and important that escaped our attention.

\section{Conflict of Interest Statement}

Dr. Yager is section editor for UpToDate for eating disorders. $\mathrm{He}$ is also an unpaid consultant for the American Psychiatric Association's Committee for Practice Guidelines and was associate editor of New England Journal of Medicine's Journal Watch Psychiatry.

Dr. Dubovsky was associate editor of the New England Journal of Medicine's Journal Watch Psychiatry. He receives research support from Intra-Cellular Therapies, Biogen, Abbvie, Boehringer Ingelheim, and Allergan.

Dr. Roy-Byrne is co-editor in chief of UpToDate for psychiatry and section editor for depression. He was editor in chief of the New England Journal of Medicine's Journal Watch Psychiatry and is now senior consulting editor for psychiatry for the New England Journal of Medicine's Journal Watch.

The authors have no additional conflict of interests to declare.

\section{Funding Sources}

There are no outside funding sources for this report.

\section{Author Contributions}

Drs. Yager, Dubovsky, and Roy-Byrne all made substantial contributions to the conception of this paper. Dr. Yager drafted this paper, and Drs. Dubovsky and Roy-Byrne contributed critical revisions for intellectual content. All of the authors had final approval of all of the submitted versions, and all are in agreement to be accountable for all aspects of this work. 


\section{References}

1 Fava GA, Guidi J. Information overload, the patient and the clinician. Psychother Psychosom. 2007;76(1):1-3.

2 SCImago. SJR - SCImago Journal \& Country Rank. [cited 2021 Mar 28]. Available from: http://www.scimagojr.com.

3 Frank CJ, Magnone P. Drinking from the fire hose: Making smarter decisions without drowning in information. New York: Penguin; 2011.

4 Phillips DP, Kanter EJ, Bednarczyk B, Tastad PL. Importance of the lay press in the transmission of medical knowledge to the scientific community. N Engl J Med. 1991 Oct;325(16):1180-3.

5 Gama Marques J, Pantovic Stefanovic M, Mitkovic-Voncina M, Riese F, Guloksuz S, Holmes K, et al. Equal access for all? Access to medical information for European psychiatrictrainees. Psychiatry Res.2016 Apr;238:150-

6 Adashi EY, Cohen IG. Industry-Sponsored Speaker Programs-End of the Line? JAMA. 2021 May;325(18):1835-6.

7 Riese F, Guloksuz S, Roventa C, Fair JD, Haravuori $\mathrm{H}$, Rolko T, et al. Pharmaceutical industry interactions of psychiatric trainees from 20 European countries. Eur Psychiatry. 2015 Feb;30(2):284-90.

8 Kretzschmar F, Pleimling D, Hosemann J, Füssel S, Bornkessel-Schlesewsky I, Schlesewsky M. Subjective impressions do not mirror online reading effort: concurrent EEGeyetracking evidence from the reading of books and digital media. PLoS One. 2013;8(2):e56178.

9 Jauhar S, Guloksuz S, Andlauer O, Lydall G, Marques JG, Mendonca L, et al.; European Federation of Psychiatric Trainees' Research Group. Choice of antipsychotic treatment by European psychiatry trainees: are decisions based on evidence? BMC Psychiatry. 2012 Mar;12(1):27.

10 Styra R. The Internet's impact on the practice of psychiatry. Can J Psychiatry. 2004 Jan;49(1):5-11.
11 Lim RF, Hsiung BC, Hales DJ. Lifelong learning: skills and online resources. Acad Psychiatry. 2006 Nov-Dec;30(6):540-7.

12 Bougioukas KI, Bouras EC, Avgerinos KI, Dardavessis T, Haidich AB. How to keep up to date with medical information using webbased resources: a systematised review and narrative synthesis. Health Info Libr J. 2020 Dec;37(4):254-92.

13 Yager J, Feinstein RE. Medical education meets pharma: moving ahead. Acad Psychiatry. 2010 Mar-Apr;34(2):92-7.

14 Yager J, Taintor Z. Endemic Publishiasis: redux and Growing. Acad Psychiatry. 2017 Dec;41(6):833-8.

15 Beall J. Predatory journals: Ban predators from the scientific record. Nature 2016;534:326.

16 Beall's list of potentially predatory journals and publishers. [cited 2021 Mar 28]. Available from: https://beallslist.net.

17 Grajales FJ 3rd, Sheps S, Ho K, NovakLauscher H, Eysenbach G. Social media: a review and tutorial of applications in medicine and health care. J Med Internet Res. 2014 Feb;16(2):e13.

18 Pizzuti AG, Patel KH, McCreary EK, Heil E, Bland CM, Chinaeke E, et al. Healthcare practitioners' views of social media as an educationalresource.PLoSOne.2020Feb;15(2):e0228372.

19 Davidson SM, Grunau Z, Marcovitz D, Gerdner OA, Stoklosa J, Vestal HS. Narrative Podcasts as a Teaching Tool in Psychiatry. Acad Psychiatry. 2019 Jun;43(3):275-9.

20 Haynes RB, McKibbon KA, Fitzgerald D, Guyatt GH, Walker CJ, Sackett DL. How to keep up with the medical literature: I. Why try to keep up and how to get started. Ann Intern Med. 1986 Jul;105(1):149-53.

21 Haynes RB, McKibbon KA, Fitzgerald D, Guyatt GH, Walker CJ, Sackett DL. How to keep up with the medical literature: II. Deciding which journals to read regularly. Ann Intern Med. 1986 Aug;105(2):309-12.

22 Scimago Journal \& Country Rank. Journal ranking [cited 2021 Mar 28]. Available from: https://www.scimagojr.com/journalrank. php.
23 Journal Impact Factor. Journal citation report: Clarivate analytics [cited 2021 Mar 28]. Available from: https://impactfactorforjournal.com/journal-impact-factor-list-2019/.

24 LIVIVO: The Search Portal for Life Sciences. [cited 2021 Apr 18]. Available from: https:// www.livivo.de.

25 Müller B, Poley C, Pössel J, Hagelstein A, Gübitz T. LIVIVO - the Vertical Search Engine for Life Sciences. Datenbank Spektrum. 2017;17(1):29-34.

26 Translators Without Borders - Wikipedia. [cited 2021 Apr 18]. Available from: https:// en.wikipedia.org/wiki/Translators_Without_Borders

27 WikiProjectMed. Translation Task Force. [cited 2021 Jun 9]. Available from: https://mdwiki.org/wiki/WikiProjectMed:Translation task_force.

28 Dubovsky SL, Dubovsky AN. Psychotropic drug prescriber's survival guide: Ethical mental health treatment in the age of big pharma. New York: WW Norton \& Company; 2007.

29 Guyatt GH, Haynes RB, Jaeschke RZ, Cook DJ, Green L, Naylor CD, et al.; EvidenceBased Medicine Working Group. Users' Guides to the Medical Literature: XXV. Evidence-based medicine: principles for applying the Users' Guides to patient care. JAMA. 2000 Sep;284(10):1290-6.

30 Haynes RB. Improving reports of research by more informative abstracts: a personal reflection. J R Soc Med. 2017 Jun;110(6):249-54

31 Montgomery JH, Byerly M, Carmody T, Li B, Miller DR, Varghese F, et al. An analysis of the effect of funding source in randomized clinical trials of second generation antipsychotics for the treatment of schizophrenia. Control Clin Trials. 2004 Dec;25(6):598-612.

32 Dubovsky SL, Balon R. We should continue to be concerned about conflicts of interest in academic medicine. Acad Psychiatry. 2021. doi: 10.1007/s40596-021-01401-6

33 Fava GA. The Age of Transition. Psychother Psychosom. 2021;90(1):1-4. 